\title{
Tratamiento de la Preeclampsia
}

\author{
Profesor Agregado: Jaime Corral Maldonado. Jefe de Clínica: Eugenio Pérez Gómez. \\ Interno: Carlos Gaitán.
}

El tratamiento profiláctico de la preeclampsia y por consiguiente de la eclampsia está basado en la estricta vigilancia de las pacientes durante el embarazo, como quiera que es un hecho aceptado que la toxemia gravídica se evita mucho más efectivamente con medidas de higiene que con tratamiento medicamentoso; por lo tanto la vigilancia médica durante el embarazo no sólo debe extremarse, sino que debe niciarse tan precozmente como sea posible y en cada consulta prenatal, que debc er mensual durante los primeros 6 meses y quincenal en el último trimestre; ha de controlarse rigurosamente el peso de la paciente, la tensión arterial, la presencia de cdemas, y la albuminuria posible. En cada consulta prenatal se instruirá a las pacientes sobre los signos y sintomas que habitualmente inician el estado preeclámptico, para que asi ella consulte al médico oportunamente.

Cuando aparece el estado preecláptico, el cual se manifiesta por un aumento progresivo o brusco de la tensión arterial, acompañado generalmente de albuminuria y edemas, de aumento exagerado del peso de cefalalgias, perturbaciones visuales, dolor epigástrico, etc., etc., lo indicado es hospitalizar a la paciente, pero si ésto no fuere posible reducirla a reposo absoluto en la cama y someterla a vigilancia mé. dica diaria. El control diario de la tension arterial, del peso, de la albuminuria, de los edemas y demás sintomas, es esencial para poder juzgar sobre la evolución de la censión y por consiguiente sobre la conducta que haya de seguirse, como quiera que un estado preecláptico aun leve debe determinar una eclampsia.

En los casos de preeclampsia leve, que muchas veces no se traduce sino por huellas de albúmina en la orina, aumento de peso semanal superior a 300 gramos, edemas ligeros y tensión arterial con máxima de 150 y mínima de 100 , debe medirse riEurosamente la cantidad de orina eliminada en 24 horas como base para apreciar la cantidad de liquido que se puede admitir que ingiera la paciente, cantidad que debe ser siempre inferior al volumen elminado. Durante las primeras 24 horas la dieta consistirá exclusivamente en 1.200 centímetros cúbicos de leche, período que según el caso puede prolongarse por uno o dos días, pasados los cuales se podrá per-mitir un régimen compuesto de 60 gramos de proteínas, 30 gramos de grasas, 400 framos de hidratos de carbono, y como máximo 1,60 gramos de cloruro de sodio, végimen que suministra 2.000 calorias.

Como complemento del régimen, y como tratamiento medicamentoso se administrará por vía oral una solución saturada de sulfato de magnesia por copas repetidas cada una o dos horas, hasta producir diarrea serosa, la cual se mantendrá en los dias siguientes con dosis más reducidas. 
Por lo general con este simple procedimiento se logra hacer bajar la tensión ar terial y hacer desaparecer los edemas. Si a pesar de dicho tratamiento la tensión ar. terial sube, aumenta la albuminuria, se acentúa la cefalalgia y las perturbaciones visuales o aparecen éstas si antes no existían, si persisten los edemas y aparece oliguria progresiva, signos que caracterizan la preeclampsia grave, se procederá sin pérdida de tiempo a obtener la sedación del sistema nervioso central y la estimulación de la diuresis.

En el Instituto se emplean desde hace muchos años el gardenal y el sulfato de magnesia por vía parenteral como sedantes del sistema nervioso y del espasmo muscular. El gardenal se puede administrar por vía oral en dosis de 0.10 a 0.30 gramos diarios o por via parenteral en dosis de 0.20 gramos cada 12 ó 24 horas, según el caso. El sulfato de magnesia se administra por vía parenteral en dosis de 5 a 10 c.c. de solución al $10 \%$ administrados intramuscularmente o de solución al $20 \%$ administrados por via intravenosa cada 8 a 12 horas según el caso. Para estimular la diuresis se emplean las soluciones concentradas de dextrosa, administradas por vía intravenosa, en la siguierte forma: Solución al $20 \%$, 500 centímetros cúbicos, solución al $33 \%$, 50 centimetros cúbicos, solución al $50 \%, 30$ centimetros cúbicos, repetidas cada 12 ó 24 horas.

De ordinario con este tratamiento desciende la tensión arterial por lo menos se mantiene estacionada, aumenta la diuresis y disminuyen los edemas. Si a pesar de èl la hipertensión se acentúa, la albuminuria aumenta, y los demás síntomas se agravan, en cualquier momento pueden aparecer las crisis convulsivas con todas sus graves consecuencias para la madre y para el niño. En tales casos habiendo sido atentamente vigilada y rigurosamente tratada la paciente, debe procederse sin dilación a provocar el parto mediante inducción médica o a extraer el feto por operación cesárea, ya que la preeclampsia grave que no cede al tratamiento mé. dico es una de las afecciones que más seriamente amenaza la vida del feto y que además puede acarrear graves consecuencias para la salud presente y futura de la madre.

El resumen de los tratamientos empleados en el Instituto fue el siguiente:

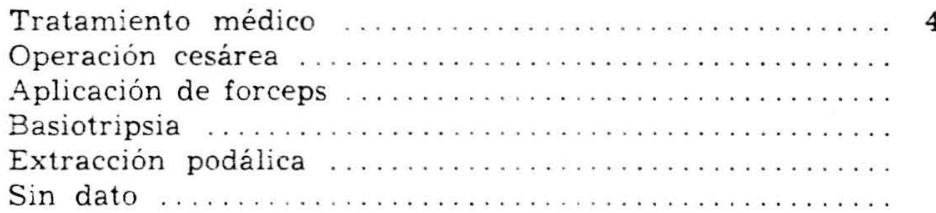

$\begin{array}{rr}465 & 75.8 \% \\ 29 & 4.6 \% \\ 63 & 10.2 \% \\ 1 & 0.1 \% \\ 1 & 0.1 \% \\ 63 & 10.2 \%\end{array}$

Total de casos

622

Las aplicaciones de forceps en la mayoria de los casos, tuvieron como única indicación la preeclampsia, pero en algunos otros a esta se asociaron otras indicaciones; la cesárea se practicó casi siempre por distocias concomitantes del estado preeclámptico. 